\title{
RELATIONSHIP OF ADOLESCENTS BEHAVIOR TO CONSUMPTION OF SOFT DRINKS IN SMPN 5 PEKANBARU YEAR 2016
}

\author{
Alhidayati, Nurhapipa, Rahma Putri \\ Program Studi Ilmu Kesehatan Masyarakat STIKes Hang Tuah Pekanbaru \\ Email: Alhidayati.skm@gmail.com
}

\begin{abstract}
Behavior consumption of soft drinks are the actions or deeds regarding how often consume soft drinks per week is calculated. Carbonated drinks consumption habits will have a negative impact when it accumulates in the long term. Have been many studies that explain the negative effects of soft drinks, including carcinogenic benzene in soft drinks is very high, high phosphate content of vital minerals in the body that can trigger heart disease (magnesium deficiency), osteoporosis (calcium deficiency) and more. Based on the survey results of the sale of soft drinks in the cafeteria, 5 schools with the highest sales level, is SMP N 5 Pekanbaru selling 6-7 boxes per month.

This type of research is quantitative with cross sectional design which was held on 16-18 May 2016 in SMP N 5 Pekanbaru. The population of this research is all student grades 7 and 8 SMP N 5 Pekanbaru which amounted to 541 people, with a sample size of 115 people. Data collected technique by stratified random sampling use questionnaire measuring instrument. Univariate data analysis and use your bivariate chi-square test. The results showed that there was a relationship between the knowledge obtained value ( $p$ value $=0.001$ value POR $=2.14)$, Effect of friends $(p$ value $=0.006$ value $P O R=3.45)$, Access $(p$ value $=0.029$ value POR $=2.70)$, And advertisement $(p$ value $=0: 01$ value POR $=3.20$ ) with the consumption of soft drinks.

Suggested to the relevant instance, that is SMP N 5 Pekanbaru to provide education and information to as many students on the impact of consuming soft drinks for health when consumed in the long term and excessive, and form healthy canteen, or supervise the beverage products, to minimize the beverage products are bad for health.
\end{abstract}

Keywords: Adolescent behaviour, Consumption of softdrink, SMPN 5 Pekanbaru

\section{PENDAHULUAN}

Minuman bersoda merupakan minuman non alkohol yang mengandung soda, sering disebut sebagai minuman ringan berkarbonasi. Remaja memilik karakteristik selalu ingin mencoba sesuatu yang baru, karakteristik tersebut menginspirasi para produsen makanan dan minuman untuk membuat makanan dan minuman yang menyegarkan, salah satu diantaranya adalah minuman ringan (Skriptiana, 2009).

Salah satu jenisnya adalah minuman bersoda atau lebih dikenal masyarakat dengan softdrink dengan komposisi air yang diberikan karbondioksida, pemanis berkalori, pewarna, asam phosphor, asam sitrat, kafein, dan pengawet seperti potassium dan sodium benzoate

Kebiasaan mengkonsumsi minuman bersodaakan menimbulkan dampak negatif bila terakumulasi dalam jangka waktu lama, dan menimbulkan penyakit (Meikawati, 2008). Kandungan fosfat yang tinggi dalam minuman bersoda dapat menghancurkan mineral penting dalam tubuh. Kekurangan mineral yang serius dapat menyebabkan penyakit jantung (kekurangan magnesium), terlebih osteoporosis (kekurangan kalsium), dan masih banyak lagi (Tilong, 2014).

Sepanjang 5 tahun (2002-2007), industri data menunjukkan bahwa total volume minuman bersoda yang dikonsumsi mengalami peningkatan di berbagai belahan dunia termasuk Indonesia. Penjualan minuman bersoda di kawasan Asia, seperti di Singapura 4,9\%, Malaysia 5,7\% dan Indonesia7,6\% per tahun (Hawkes, 2010).

Menurut Ratnaningtyas, Direktur Industri Minuman dan Tembakau Ditjen Industri Agro Kementerian Perindustrian (Kemenperin RI) menyatakan bahwa,Industri minuman ringan berkarbonasi (non alkohol) diprediksi tumbuh $2,6 \%$ tahun ini

Berdasarkan hasil survey dari

10 sekolah, penjualan minuman bersoda dengan tingkat penjualan tertinggi, adalah SMP N 5 Pekanbaru yang menjual 6-7 kotak perbulannya Berdasarkan pertimbangan tersebut peneliti tertarik untuk mengetahui Hubungan 
Perilaku Remaja terhadapKonsumsi Minuman Bersoda di SMP Negeri 5 Pekanbaru tahun 2016.

Tujuan penelitian ini adalah diketahuinya Hubungan antara perilaku remaja terhadap konsumsi minuman bersoda di SMPN 5 Pekanbaru tahun 2016

\section{METODOLOGI PENELITIAN}

Jenis penelitian ini adalah analitik kuantitatif dengan desain penelitian Cross Sectional yang dilaksanakan mulai bulan Mei tahun 2016 diSMP N 5 Pekanbaru. Jumlah sampel dalam penelitian ini sebanyak 105 orang, dengan populasi sebanyak

541 orang. Jenis data yang dikumpulkan adalah data primer berupa lembar kuesioner dan data primer berupa arsip jadi data siswa dari pihak sekolah. Analisis data dilakukan dengan system kompeterisasi SPSS dengan uji ChiSquare.

\section{HASIL DAN PEMBAHASAN} Hasil

\section{Analisis Univariat}

Analisis univariat dalam penelitian ini meliputi konsumsi minuman bersoda, pengetahuan, pengaruh teman, akses dan pengaruh iklan terhadap konsumsi minuman bersoda. Hasil penelitian tentang analisis

\section{Tabel 1}

Distribusi Frekuensi Responden Berdasarkan Variabel Dependen dan Variabel Independen di SMP N 5 Pekanbaru Tahun 2016.

\begin{tabular}{ccc}
\hline Variabel & Frekuensi & Persentase (\%) \\
\hline Perilaku Konsumsi Minuman Bersoda & 60 & 60.0 \\
Sering Jarang & 40 & 40.0 \\
\hline Total & $\mathbf{1 0 0}$ & $\mathbf{1 0 0 . 0}$ \\
\hline Pengetahuan Rendah Tinggi & 52 & 52.0 \\
& 48 & 48.0 \\
\hline Total & 100 & 100 \\
\hline Pengaruh Teman sebaya & 53 & 53.0 \\
Terpengarauh Tidak Terpengaruh & 47 & 47.0 \\
\hline Total & $\mathbf{1 0 0}$ & $\mathbf{1 0 0 . 0}$ \\
\hline Akses Mudah Sulit & 57 & 57.0 \\
\hline
\end{tabular}




\begin{tabular}{ccc}
\hline & & 43 \\
\hline Total & $\mathbf{1 0 0}$ & 43.0 \\
\hline & & $\mathbf{1 0 0 . 0}$ \\
Pengaruh Iklan Terpengaruh Tidak terpengaruh & 52 & 52.0 \\
& 48 & 48.0 \\
\hline Total & $\mathbf{1 0 0}$ & $\mathbf{1 0 0 . 0}$ \\
\hline
\end{tabular}

\section{Tabel 2}

Distribusi Hubungan Perilaku remaja dengan konsumsi minuman bersoda di SMP N 5 Pekanbaru Tahun 2016

\begin{tabular}{|c|c|c|c|c|c|c|c|c|c|}
\hline \multirow{3}{*}{ No. } & \multirow{3}{*}{ Variabel } & \multicolumn{4}{|c|}{ Konsumsi Min. Bersoda } & \multirow{2}{*}{\multicolumn{2}{|c|}{ Total }} & \multirow{3}{*}{ Pvalue } & \multirow{3}{*}{$\begin{array}{c}\text { POR } \\
(95 \% \mathrm{CI})\end{array}$} \\
\hline & & \multicolumn{2}{|c|}{ Sering } & \multicolumn{2}{|c|}{ Jarang } & & & & \\
\hline & & n & $\%$ & n & $\%$ & $\mathrm{~N}$ & $\%$ & & \\
\hline \multirow[b]{3}{*}{1.} & Pengetahuan & & & & & & & \multirow{3}{*}{0,001} & \multirow{2}{*}{$\begin{array}{c}2,14 \\
(5.08-\end{array}$} \\
\hline & Rendah & 40 & 76.9 & 12 & 23.1 & 52 & 100 & & \\
\hline & $\begin{array}{c}\text { Tingori } \\
\text { Total }\end{array}$ & $\begin{array}{l}20 \\
60 \\
\end{array}$ & $\begin{array}{l}417 \\
60.0\end{array}$ & $\begin{array}{l}38 \\
40 \\
\end{array}$ & $\begin{array}{l}58.3 \\
40.0\end{array}$ & $\begin{array}{l}48 \\
100\end{array}$ & $\begin{array}{l}1 \mathrm{n} n \\
100\end{array}$ & & ก ก9) \\
\hline \multirow{4}{*}{2.} & Peng. Teman Sebaya & & & & & & & \multirow{4}{*}{0,006} & \multirow{4}{*}{$\begin{array}{c}3,45 \\
(1,49 . \\
7,97)\end{array}$} \\
\hline & Terpengaruh & 39 & 73.6 & 14 & 26.4 & 53 & 100 & & \\
\hline & Tidak terpengaruh & 21 & 44.7 & 26 & 55.3 & 47 & 100 & & \\
\hline & Total & 60 & 60.0 & 40 & 40.0 & 100 & 100 & & \\
\hline \multirow{4}{*}{3.} & Akses & & & & & & & \multirow{4}{*}{0,029} & \multirow{4}{*}{$\begin{array}{l}2,70 \\
(1.18 \\
6.17)\end{array}$} \\
\hline & Mudah & 40 & 70.2 & 17 & 29.8 & 57 & 100 & & \\
\hline & Sulit & 20 & 46.5 & 23 & 53.5 & 43 & 100 & & \\
\hline & Total & 60 & 60.0 & 40 & 40.0 & 100 & 100 & & \\
\hline \multirow{4}{*}{4.} & Peng. Iklan & & & & & & & \multirow{4}{*}{0,01} & \multirow{4}{*}{$\begin{array}{l}(1,39- \\
7.39)\end{array}$} \\
\hline & Terpengaruh & 38 & 73.1 & 14 & 26.9 & 52 & 100 & & \\
\hline & Tidak terpengaruh & 22 & 45.8 & 26 & 54.2 & 48 & 100 & & \\
\hline & Total & 60 & 60.0 & 40 & 40.0 & 100 & 100 & & \\
\hline
\end{tabular}

\section{Pembahasan}

Hubungan Pengetahuan Responden dengan Konsumsi Minuman bersoda

Berdasarkan hasil penelitian tentang hubungan yang dilakukan diketahui sebanyak 60 responden sering mengkonsumsi minuman bersoda dan berdasarkan hasil uji statistik, terdapat hubungan yang signifikan antara pengetahuan dengan konsumsi minuman bersoda di SMP N 5 Pekanbaru tahun 2016. Dengan nilai $P$ value $=0.001$ dan $\mathrm{POR}=2.14$.

Hasil penelitian ini sesuai dengan teori Notoatmodjo (2007), dimana pengetahuan merupakan domain yang sangat penting untuk terbentuknya tindakan seseorang.Penelitian ini juga sejalan dengan penelitian yang dilakukan oleh Fauzia (2012), tentang "hubungan pengetahuan gizi dengan konsumsi minuman bersoda pada Siswa SMP Islam PB Soedirman Jakarta Timur Tahun 2012", menunjukkan $p$ - value $0,008(\mathrm{p}<0,05)$ artinya ada hubungan yang signifikan antara pengetahuan gizi dengan konsumsi minuman bersoda.

Menurut pendapat peneliti bahwa responden yang berpengetahuan rendah cenderung lebih sering mengkonsumsi minuman bersoda.Rendahnya pengetahuan dapat dilihat dari masih banyaknya responden (67 orang) yang tidak mengetahui kandungan apa saja yang terdapat dalam minuman bersoda.

\section{Hubungan Pengaruh Teman Sebaya dengan Konsumsi Minuman bersoda}

Berdasarkan hasil uji statistik, terdapat hubungan yang signifikan antara pengaruh teman sebaya dengan konsumsi minuman bersoda di SMP N 5 Pekanbaru tahun 2016. Dengan nilai $P$ value $=0.006$ danPOR $=3.4$.

Peneliti berasumsi bahwa teman sebaya sangat berpengaruh besar dalam menentukan 
jenis makanan dan minuman yang dikonsumsi remaja, dalam hal ini minuman bersoda. Hal ini dapat dilihat dari banyaknya responden (47 orang) yang menyatakan mengkonsumsi minuman bersoda pada saat istirahat sekolah dan berkumpul dengan teman dan sebagian besar responden mengaku ikut membeli minuman bersoda, pada saat teman-temannya membeli minuman bersoda.

\section{Hubungan Akses dengan Konsumsi Minuman bersoda}

Berdasarkan hasil uji statistik, terdapat hubungan yang signifikan antara pengaruh akses dengan konsumsi minuman bersoda di SMPN 5 Pekanbaru tahun 2016. Dengan nilai $P$ value $=$ 0.029 dan $\mathrm{POR}=3.4$.

Sejalan dengan teori Pipes (1985) dalam Ariani (2012), bahwa kemudahan akses terhadap makanan dan minuman siap konsumsi, merupakan faktor yang mempengaruhi kebiasaan makan dan minum remaja. Menurut Fauzia (2012), ketersedian minuman bersoda dalam lingkungan sekolah yang mudah diakses akan mempengaruhi perilaku konsumsi siswa. Penelitian ini juga sejalan dengan penelitian fauzia (2012) tentang hubungan antara aksesibilitas dengan kebiasaan konsumsi minuman bersoda pada SMP PB Soedirman tahun 2012, dengan hasil uji statistik $p$ value $=$ $0.026(\mathrm{p}<0.05)$.

Peneliti berasumsi bahwa akses dapat mempengaruhi perilaku konsumsi minuman bersoda. SMP N 5 Pekanbaru, memperbolehkan secara bebas penjualan minuman bersoda yang dapat ditemui hampir pada setiap kantin sekolahnya dan siswa-siswi SMPN 5 Pekanbaru menyatakan paling banyak membeli minuman bersoda di kantin sekolah.Hal ini tentunya memudahkan akses siswa-siswi untuk mendapatkan minuman bersoda, ditambah lagi sebagian besar waktu yang dihabiskan responden berada disekolah apalagi lokasi kantin di SMP N 5 Pekanbaru mempunyai jarak yang dekat dengan sekolah

\section{Hubungan pengaruh iklan dengan konsumsi Minuman bersoda}

Berdasarkan hasil uji statistik, terdapat hubungan yang signifikan antara pengaruh iklan dengan konsumsi minuman bersoda di SMP N 5 Pekanbaru tahun 2016. Dengan nilai $P$ value $=$ 0.01 dan $\mathrm{POR}=3.2$.

Penelitian ini sejalan dengan pendapat Skriptiana (2009) dan Verzeltti, et al (2010) yang menyatakan bahwa pengaruh media massa dapat meningkatkan konsumsi minuman bersoda pada remaja. Hasil penelitian ini juga sejalan dengan penelitian Fauzia (2012) tentang "Hubungan antara media massa dengan kebiasaan konsumsi minuman bersoda pada siswa SMP Islam PB

Sejalan dengan teori Soetjiningsih, (2004) menyatakan pengaruh teman sebaya sangat kuat pada masa remaja, yang menyebabkan perubahan gaya hidup, perilaku, dan pengalaman dalam menentukan makanan dan minuman yang dikonsumsi. Skriptiana (2009) menyebutkan, bahwa pengaruh teman sebaya dapat meningkatkan konsumsi minuman bersoda remaja.

Penelitian ini juga sejalan dengan penelitian Fauzia (2012), tentang "Hubungan antara Teman sebaya dengan Konsumsi Minuman Bersoda pada Siswa SMP Islam PB Soedirman Jakarta Timur Tahun 2012", menunjukkan p-value ", dengan hasil uji statistik Chi-Square menunjukkan $p$-value $=0,000(\mathrm{p}-$ value $<0.05)$, artinya ada hubungan yang signifikan antara pengaruh teman sebaya dengan konsumsi minuman bersoda

Soedirman tahun 2012", yang menunjukkan $P$ value $=0.000$, yang artinya ada hubungan yang signifikan antara media massa dengan konsumsi minuman bersoda. Dengan nilai POR=6.51 .

Peneliti berasumsi bahwa iklan komersial tentang minuman bersoda khususnya di televisi cukup mempengaruhi remaja dalam mengkonsumsi minuman bersoda. Dari 100 responden, sebanyak 92 orang menyatakan mengetahui minuman bersoda dari televisi, dan sebanyak 59 responden menyatakan tertarik untuk mengkonsumsi minuman bersoda karena iklan yang didengar maupun dilihat. Minuman bersoda yang digambarkan dalam iklan penuh dengan keceriaan, kebersamaan, semangat dan 
ditambah lagi dengan bintang iklan yang didominasi oleh remaja sebagai ikon utama.

\section{KESIMPULAN DAN SARAN}

\section{Kesimpulan}

Berdasarkan uraian pada hasil penelitian dan pembahasan mengenai hubungan perilaku remaja dengan konsumsi minuman bersoda di SMP N 5 Pekanbaru tahun 2016, sebanyak 60 orang (60\%), responden sering mengkonsumsi minuman bersoda, maka dapat disimpulkan sebagai berikut:

1. Ada hubungan antara pengetahuan dengan perilaku konsumsi minuman bersoda di SMP N 5 Pekanbaru tahun 2016. Dengan $P$ Value $=0.01(\mathrm{p}<0.05)$ dan nilai $\mathrm{POR}=2.14$.

2. Ada hubungan antara pengaruh teman sebaya dengan perilaku konsumsi minuman bersoda di SMP N 5 Pekanbaru tahun 2016. Dengan $P$ Value $=0.006(\mathrm{p}<0.05)$ dan nilai $\mathrm{POR}=$ 3.45 .

3. Ada hubungan antara akses dengan perilaku konsumsi minuman bersoda di SMP N 5 Pekanbaru tahun 2016. Dengan $P$ Value $=$ $0.029(\mathrm{p}<0.05)$ dan nilai $\mathrm{POR}=2.70$.

4. Ada hubungan antara pengaruh iklan dengan perilaku konsumsi minuman bersoda di SMP N 5 Pekanbaru tahun 2016. Dengan $P$ Value $=0.01(\mathrm{p}<0.05)$ dan nilai POR $=3.20$.

\section{Saran}

\section{SMP N 5 Pekanbaru}

Perlu dilakukan penyuluhan (edukasi) dan memberikan informasi sebanyak mungkin kepada siswa-siswi tentang dampak minum bersoda bagi kesehatan. Diharapkan juga bagi pihak sekolah untuk membentuk kantin sehat ataupun melakukan pengawasan terhadap produk - produk minuman maupun jajanan yang ditawarkan di kantin SMP N 5 Pekanbaru,

\section{Bagi STIKes Hang Tuah Pekanbaru}

Bagi stikes Hang Tuah Pekanbaru dapat memberikan kontribusi ilmiah dalam ruang ilmu kesehatan masyarakat, khususnya peminatan promosi kesehatan dan ilmu perilaku serta dapat menjadi tambahan bacaan perpustakaan STIKes
Hang Tuah Pekanbaru. Dapat menjadi bahan referensi bagi mahasiswa lain yang melakukan penelitian sejenis.

\section{Bagi Peneliti Selanjutnya}

Bagi peneliti selanjutnya agar dapat melakukan observasi lebih lanjut dengan menambah variabel-variabel lain seperti uang saku, peran orang tua, sikap, body image (kesan tubuh) dan lainnya, dengan desain penelitian yang berbeda, misalnya dengan desain study kohort atau case control sehingga dapat menggali lebih dalam lagi mengenai hal-hal yang berhubungan dengan perilaku konsumsi minuman bersoda.

\section{UCAPAN TERIMA KASIH}

Kepada pihak SMPN 5 Pekanbaru yang telah memberikan kesempatan kepada peneliti untuk melaksanakan penelitian. Serta Ucapan Terima Kasih Kepada Responden Hingga Penelitian ini dapat diselesaikan.

\section{DAFTAR PUSTAKA}

American Beverage Associatin.(2012) Beverage Igridients. (Online) (www.ameribev.org. Diakses 3 Desember 2015)

Arisman, M. (2006). Gizi dalam Daur Kehidupan Jakarta : EGC.

Azwar, S. (2011).Sikap Manusia, Teori dan Pengukurannya. Yogyakarta : Pustaka Pelajar

Buckle, A., Edwards, A.R., Fleet, H.G., \& Wootton, M. (1987) Ilmu Pangan. Terjemahan oleh Hari purnomo Adiono, (2011).Jakarta : UI-Press.

Cheng, R., Yang, H., Shao, Y. et al. 2009. Dental Erosionand severe Tooth decay Related to Soft Drink: A case Report and Literature Review. Journal of Zheijang University Science vol. 10 no 5 , pp 395399.

Online) http://search.proquest.com/.Dia kses 25 Desember 2015

Cuomo, R., Savarese, F., Sarnelli, G., et al. (2011) The role of pre load beverage on gastric volume and food intake:

Comparison between noncaloric 
carbonated and non carbonated

beverage. Nutrion Jurnal,10: 114

(Online)

(http://www.nutritionj.com/cont

ent/10/1/114 Di akses 20 Januari 2016)

Departemen Gizi dan Kesehatan Masyarakat Fakultas Kesehatan Masyarakat UI.(2011). Gizi dan keseshatan Masyarakat.Jakarta: Rajawali Pers.

Desnita, (2014).Hubungan Pengetahuan, Sikap siswa dan Kebijakan Khusus Pihak Sekolah Negeri Terhadap perilaku Merokok Di SMA Negeri 11 Pekanbaru Tahun 2014. Proposal penelitian Peminatan Promosi kesehatan dan Ilmu Prilaku Program Studi Ilmu Kesehatan Masyarakat (STIKes) Hangtuah Pekanbaru.

Dilapanga, A. (2008). Faktor-faktor yang berhubungan dengan perilaku konsumsi soft drinks pada siswa Smp negeri 1 ciputat tahun

2008.SkripsiPeminatan Gizi Kesmas Fakultas Kedokteran dan Ilmu Kesehatan Universitas Islam Negeri Syarif Hidayatullah, Jakarta.

Fauzia, A. (2012) Hubungan Faktor Individu dan Faktor Lingkungan dengan Kebiasaan Konsumsi Minuman Bersoda pada Siswa SMP Islam PB Soedirman Jakarta Timur Tahun 2012. Skripsi Peminatan Gizi Kesehatan Masyarakat Fakultas Kesehatan Masyarakat Universitas Indonesia, Depok.

Fury, E. Hariyatmi. 2014. Kadar Asam Urat

Darah Pada Mencit (Mus Musculus) Dengan Pemberian Minuman Berkarbonasi.(Skripsi)Fakultas

Keguruan Dan Ilmu Pendidikan Universitas Muhammadiyah Surakarta

Gibney,Michael J. et al. (2004) Gizi kesehatan Masyarakat. Terjemahan oleh Palupi Widya Astuti dan Erita Agustin Hardiyanti.Jakarta : EGC

Hartono, Andry. (2005). Gizi Kesehatan Masyarakat.Alih bahasa dari buku Gibney, Michael, J. Public Health
Nutrition.Jakarta : Penerbit buku Kedokteran (EGC)

Hawkes, Corinna. (2010). The wordwide Battle Against Soft Drinks in Schools. American Journal of preventive Medicine vol. 38 no.4, pp. 457-4461 (online) (www.ajpm-online.net. Diakses 28 januari 2016)

Holistic Health Solution, (2011).Osteoporosis di Usia Muda.Jakarta : PT. Gramedia Widiasarana Indonenesia.

Kasjono, S. Yasril. (2009). Teknik sampling untuk Penelitian Kesehatan. Yogyakarta : Graha ilmu

Kemenperin RI.(2015) Industri Minuman Ringan Ditaksir Tumbuh 2,6\%. (Online) (http://www.kemenperin.go.id/ artikel/8411/Industri-Mi Ringan Ditaksir-Tumbuh-2 akses 3 Desember 2015)

Kemenperin RI.(2015) Industri Minuman Ringan Ditaksir Tumbuh2,6\%.(Online) (http://www.kemenperin.go.id/ artikel/8411/Industri-Minuman-_Ringan Ditaksir-Tumbuh-2,6 di akses 3 Desember 2015)

Lim, S. et al. 2008.The Association between soft drinks consumption caries risk among low-income African-american children is not clear. Journal of Evidence Based Dental Practice 139 (7) (Online) http://www.jstor.comdiakses 25 Desember 2015

Malik, S., Vasanti, et al. (2006) intake sugarsweetened beverages and weight gain : a systematic review. American journal of clinical nutrition. Vol 84, no 2, 274-288. (online) (ajcn.nutrition.org/ di akses 26 januari 2016)

Meikawati, W. (2008).Hubungan kebiasaan mengkonsumsi makanan dan minuman Berkarbonat dan berkafeein dengan kepadatan tulang remaja (studi di SMAN 3 Semarang.Jurnal Kesmas Vol 4 no 2 Th 2008.

(Online) (http://jurnal.unimus.ac.id_di akses 14 Januari 2016). 
Michael M, Joseph. The health effect of drinking soda. Encyclopedia of natural Medicine, revised second edition. (Online) (di akses 25 Desember 2015 http://www.google.com)

Muthmainnah, (2009), Faktor-faktor yang Mempengaruhi Konsumsi Minuman Ringan Berkarbonasi pada Mahasiswa Program Studi Administrasi Bisnis PNJ 2009. (Skripsi) Fakultas Ilmu Keperawatan Program Studi Ilmu Keperawatan Depok.

Notoatmodjo, S. (2007) Promosi Kesehatan dan Ilmu prilaku. Jakarta :Rineka Cipta

Notoatmodjo, S. (2012), Promosi Kesehatan dan Prilaku Kesehatan.Jakarta : Rineka Cipta

Nuraini, H. (2007), Memilih \& Membuat Jajanan Anak yang Sehat dan Halal. Jakarta: QultumMedia

Pipes, Peggy, L. (2000).Nutrition in infancy and childhood. St Louis, Misouri : Times Mirror/mosby College Publishing.

Poltekkes (2011).Kesehatan Remaja Problem dan Solusinya.Jakarta: Salemba Medika

Raviany, Sepala (2011). Analisis pengaruh efektivitas iklan Pesaing dan perilaku mencari variasi Terhadap perilaku perpindahan Merek pada konsumen

Tehbotol sosro (Sk Fakultas Ekonomi Unive Dipenogoro Semarang.

Riyanto, A. (2011) Aplikasi Metodologi Penelitian Kesehatan. Yogyakarta : Nuha Medika

Sarkim, L. et al, (2010), Prilaku Konsumsi Mie Instant pada Mahasiswa Fakultas Kesehatan Masyarakat Undana Kupang yang Tinggal di Kos Wilayah Naikoten 1.Jurnal FKM Undana (Online) (www. SolidDocuments.com 20 september 2015)

Sartika, D., A (2011). Faktor Risiko Obesitas Pada Anak 5-15

Tahun Di Indonesia.Makara Kesehatan Vol. 15,no1 37-43 Departemen Gizi Kesmas FKM UI (Online) (http://journal.ui.ac.id/index.ph $\mathrm{p} /$ health/article/download/796/7 58 diakses 20 januari 2016)
Setyawati, V., Setyowati, M. (2015) Karakter gizi remaja putri urban dan rural di provinsi. Jurnal Kesmas Universitas

Negeri Semarang (1) no 43-52. ISSN:1858-1196 Jawa tengah. (Online) (http://journal.unnes.ac.id/nju/i ndex.php/kemas Diakses 1 januari 2016)

Sidiq, W. (2010).Hubungan antara persepsi terhadap iklan komersial diTelevisi dengan intensi membeli pada Produk minuman berkarbonasi.Skripsi psikologi fakultas psikologi Universitas muhammadiyah Surakarta.

Skriptiana, R.A (2009), Hubungan Antara pengetahuan Gizi, Teman Sebaya, Media massa, dan Faktor lain dengan konsumsi minuman ringan Berkarbonasi pada Siswa-siswi SMPIT Nurul Fikri Tahun 2009. Skripsi Peminatan Gizi Kesehatan Masyarakat Fakultas Kesehatan Masyarakat Universitas Indonesia, Depok.

Setyadi, Nugroho, J. (2008). Perilaku konsumen: konsep dan implikasi untuk strategi dan pemasaran.Jakarta : Kencana Prenada Media Group.

Soetjoningsih, (2004).Tumbuh Kembang Remaja dan permasalahnnya.Jakarta : CV. Sagung Seto.

Tahmassebi et al. 2006.Soft Drinks and Dental Health: A review of The Current Literature. PubMed Journal vol. 34 no. $1 \quad p p . \quad 2-11 \quad$ (online) (http://www.ncbi.mlm.nih.gov/. diakses 25 Desember 2015)

Tandra, H. (2009). Segala Sesuatu yang Harus Anda Ketahui tentang Osteoporosis.Jakarta: PT Gramedia Pustaka Utama

Tilong, D.A, (2014). Penyakit- penyakit yang di Sebabkan Makanan dan Minuman pada Anak.Jogjakarta : Laksana..

Utami, W. (2012).Hubungan Konsumsi Zat Gizi Karakteristik Keluarga dan faktor lainnya terhadap remaja gizi lebih di SMPN 41 Jakarta selatan.Skripsi Peminatan Gizi Kesehatan Masyarakat 
Fakultas Kesehatan Masyarakat Universitas Indonesia, Depok.

Verzletti, et al(2010).Softdrinks Consumption of Adolescence: Association with food_Related Lifestyles and Family Rules in belgium flanders and the Veneto Region Italy", Europeanjurnal of public health vol 20 no 3.(Online) (http://europub.oxfordjournals. org/ diakses 5 juni 2016)
Wahyuningsih, M. (2011) Kenapa minum soda bikin gemuk?

(Online) (http://www.detikhealth.com/re ad/2011/03/19/120510/ kenapa- minumsodabikin- gemuk? Hlight diakses 12 Desember 2016).

Widyatama, R. (2009). Pengantar periklanan.Yogyakarta : Pustaka Blook Publisher

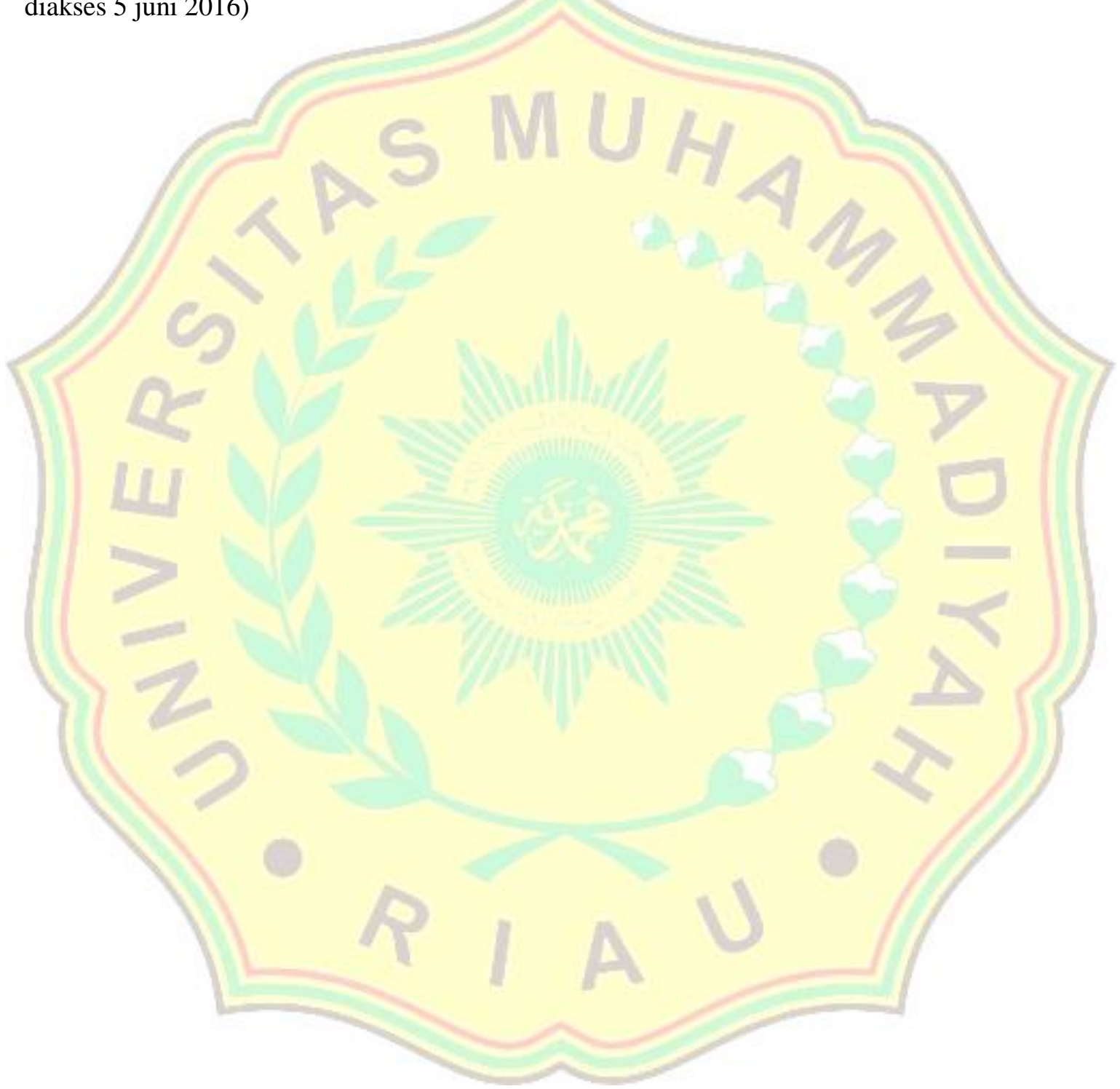

